International Journal of Engineering \& Technology, $7(3.2)(2018) 291-298$
International Journal of Engineering \& Technology
Website $:$ www.sciencepubco.com/index.php/IJET
Research paper

\title{
Effective Structural System for the Affordable Housing Construction
}

\author{
Andrii Pavlikov $^{1}$, Serhii Mykytenko ${ }^{2}$, Anton Hasenko ${ }^{3 *}$ \\ ${ }^{1}$ Poltava National Technical Yuri Kondratyuk University, Ukraine \\ ${ }^{2}$ Poltava National Technical Yuri Kondratyuk University, Ukraine \\ ${ }^{3}$ Poltava National Technical Yuri Kondratyuk University, Ukraine \\ *Corresponding Author E-Mail: Gasentk@Gmail.Com
}

\begin{abstract}
This article falls within vital question in quickly builds construction - theoretical method for calculating the slabs and columns of such buildings. Calculation research of buildings with reinforced concrete frame slabs is described in the article. The features of work the collapsible flat plate ceiling in composition of reinforced concrete framework of building are analyzed. Problems in the design of framework building are considered in order to increase its reliability. The suggestions for directions of perfection the calculation of flat plate frame construction elements are proposed in the article. The novelty of this work is to get new theoretical data about bearing capacity and deformability of structural system for the affordable housing construction from reinforced concrete.
\end{abstract}

Keywords: flat plate ceiling, reinforced concrete framework building, low-cost housing beam.

\section{Introduction}

The current stage of construction is characterized by the problem of need to reduce the cost of buildings and structures by reducing the complexity of their construction, material cost saving, the use of energy saving fencing structures. One solution to this problem is the use of industrial constructions, which have considerable advantages over monolithic. Today, there are many examples of effective use of such structures, both in new construction and in the process of reconstruction. Industrial skeleton without using beams and capitals (system of "KUB" type) stands out clearly among them. It was adopted from the late $60 \mathrm{~s}$ of the last century and today has been improved during its use in solving problems of the program providing people with affordable housing [1].

Application of this framework has almost solved the contradiction between strength and resistance to heat transfer of wall materials in wall buildings by separating the bearing and guarding functions of the walls. Because of this, the skeleton without using beams and capitals has become more widespread in recent times [2-3]. In 2008 according to the projects of the State Design Institute for Urban Development "Miskbudproekt" within the program of experimental construction system "KUB" [4] in buildings of affordable housing, as well as in other buildings (Fig. 1) was applied for the first time in the city Poltava.

\section{Analysis pf Recent Research and Publica- tions}

Constructive system without using beams and capitals has not been sufficiently studied so far as evidenced by the [5] static calculation for a system of perpendicular frames. But this approach does not reflect the actual work of the frame elements within the building and therefore leads to inefficient use of armature.
Also in the calculations the junction of a column with overlap is considered to be a spline. But in this node point there cracks arising from the effects of bending moment in the plate, which significantly reduces the initial height of the spline, turning it into an unknown value.

Constructive system without using beams and capitals is proposed to apply as the most effective one among others for the construction of affordable housing.

The feature of constructive system without using beams and capitals is the absence of its traditional beam crossbars which results in using of multistory columns without consoles. Prefabricated plates of overlap are combined by a loop joint in a solid disk that locally rests directly on the columns through the plates over columns. The spatial rigidity and stability of such a frame, which can work according to the frame or frame-visage scheme, depending on the design decisions, must be ensured by the reliable operation of monolithic joints between the elements [5].

Preliminary experimental data [6 - 9] testify that some features of the combined overlap under load in its working process are characterized by the presence of cracks in two directions of any plate. These features can be explained by the differences in the transfer of load from the plates to the columns compared with the beam overlaps. So, in traditional beam systems, the load is transmitted sequentially: from plates to beams and then on console columns. Thus the overlap in constructive systems without using beams and capitals rests directly through the plates on the columns, then the static work of such a system is characterized by collecting the vertical load on the column from all directions along the shortest distances. It should be noted that the nature and character of the cracks formation in the overlap depend on the method of its manufacture [10]. So, in a blocked overlap of constructive system without using beams and capitals the cracking process in plates differs from the cracking process in a plate of monolithic overlap. 


\section{Formulating of the Article's Goals}

Despite the fact that the method of calculating the systems without using beams and capitals is described in [5], today there are still many unsolved problems. Among them as evidenced by the

a)

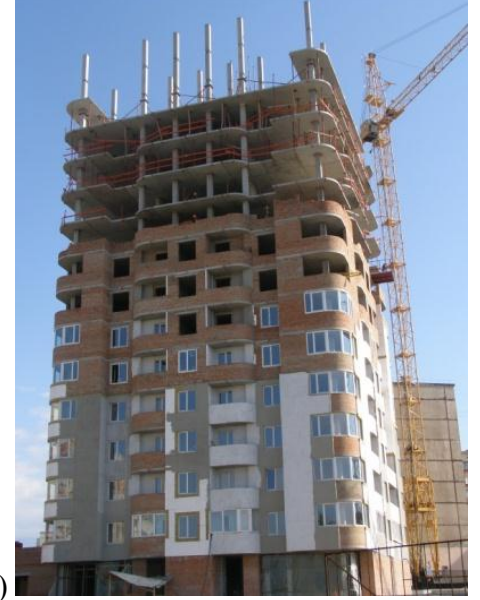

b)
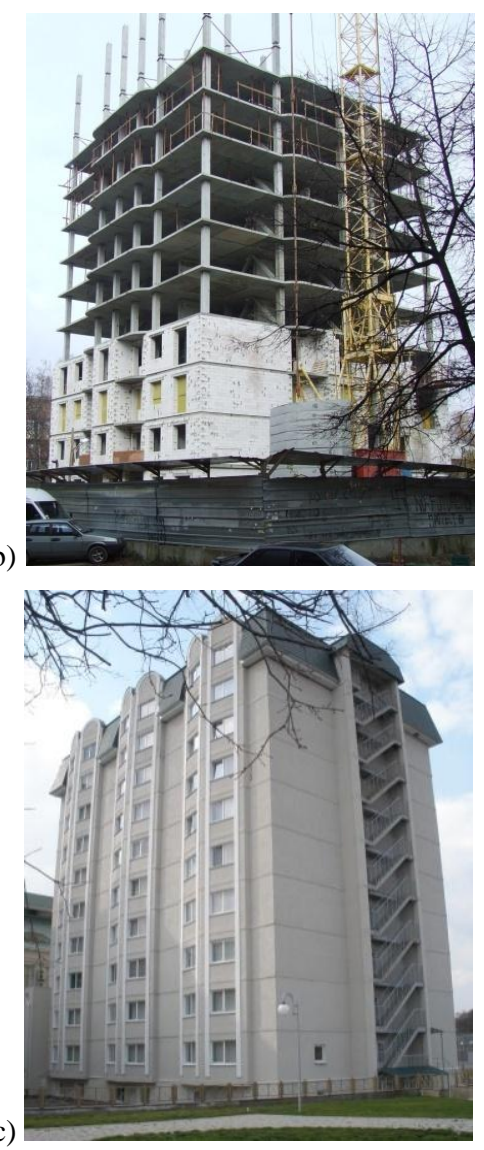

d)

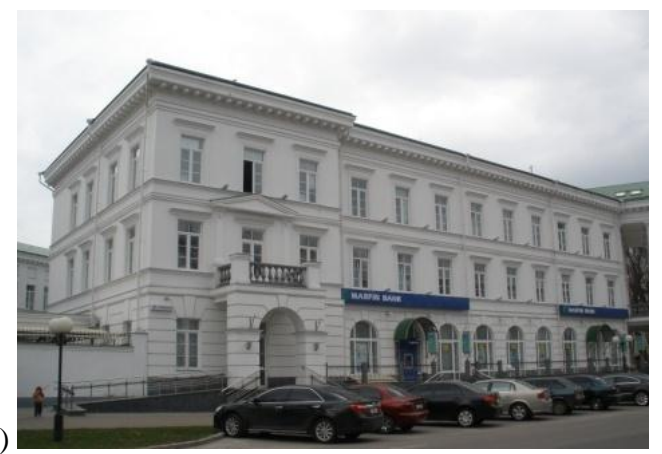

Fig. 1: Buildings in Poltava: a) residential 16-storeyed on Bohdan Khmelnytsky avenue, 21; b) residential 16-storeyed in Sobornosti street, 60; c) hostel in Pershotravnevyi avenue, 5; d) office centre in European street, 2. results of experimental and theoretical studies [5] is ignoring the presence of significant strength reserves in such constructive systems. Therefore, this work is aimed at research the task of calculating the bearing capacity of overlap plates and columns in constructive systems without using beams and capitals

\section{The Main Material with the Justification of New Scientific Results}

If you analyze the work of the overlay disk as a system of connected combined plates, it appears that the load transfer sequence is the same as shown in Figure 2. Therefore, the reinforcement of plates is rationally made by the calculations, which implement the scheme of load transfer from the plate to the plate. Also, with such a load transfer scheme, each plate will have its own destruction scheme.

a)
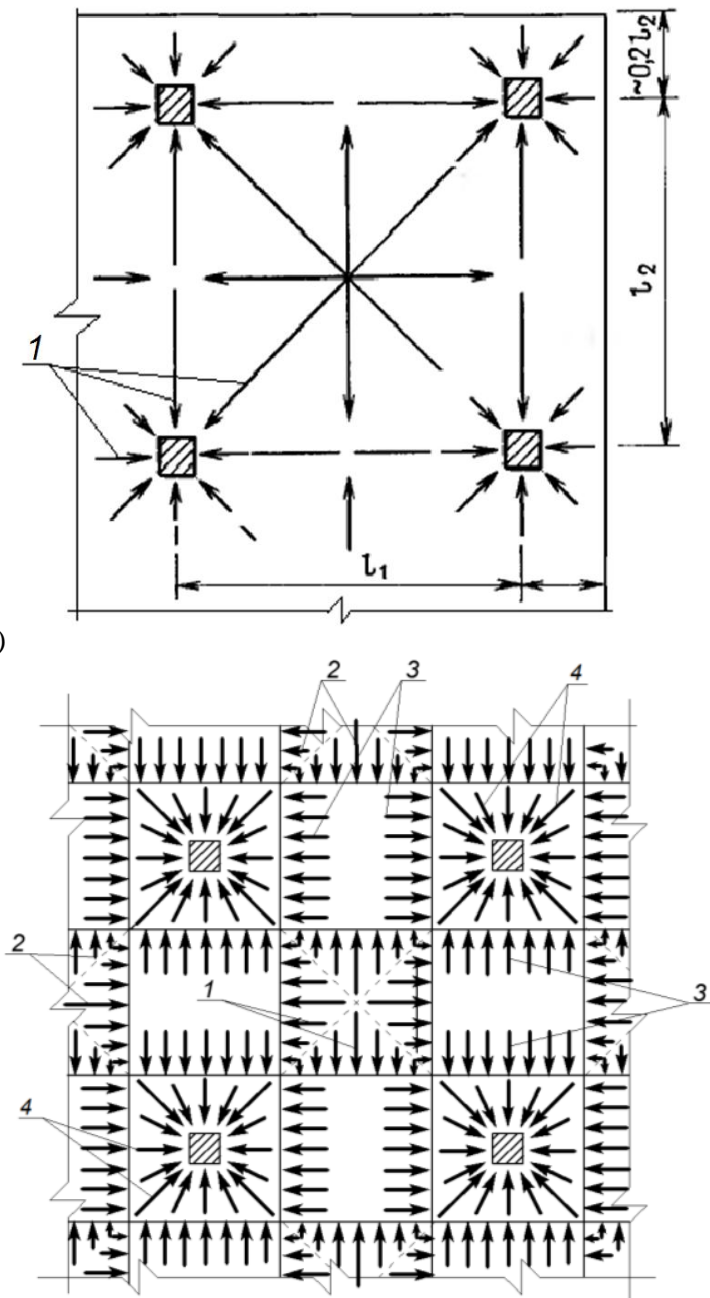

Fig. 2: Schemes for gathering loads on columns: a) in monolithic frames without using beams; b) in prefabricated frames without using beams and capitals: 1 - directions for transferring loads to columns; 2 - from plates above columns to a columns; 3 - from plates between columns to plates above columns; 4 - from the middle plates to plates between columns.

The basis of the calculation is the kinematic way of the boundary equilibrium method, which allows to apply the equation of equilibrium between the virtual work of external and internal efforts on possible appropriate offsets in the direction of the load $q, P_{j}$, and effort $M_{i}[11]$ :

$\int_{A} y_{q} \times q \times d A+\sum_{j=1}^{k} P_{j} y_{j}=\sum_{i=1}^{n} M_{i} \times j_{i} \times l_{i}$, 
where $y_{q}$ - the displacement of the plate from the $\operatorname{load} q ; y_{j}$ the displacement of the plate from the load $P_{j} ; M_{i}-$ the moment in the $i$ - th linear plastic hinge per unit of its length; $\varphi_{i}$ - the angle of the disk rotation in the $i$-th linear plastic hinge; $l_{i}-$ the length of the $i$-th plastic hinge; $n$-number of examined sections of linear plastic hinges.

Internal efforts in plates are distributed unevenly; therefore it is advisable to reinforce the plate in accordance with the method of constructing a diagram of materials with the breakage of longitudinal armature.

The methodology of calculation is based on the following assumptions:

Two cases of the plates' destruction in the limiting state of the plate are considered (Fig. 3);

plates have breaks of working reinforcement rods along the length along the sides, which are based on plates above the columns, at the same time the condition of equal strength of the plates is fulfilled in the first and second cases of destruction (Fig. 3);

- at the moment of reaching by construction the state of limit equilibrium the tension in armature reaches values corresponding to the yield point of steel $\mathrm{f}_{\mathrm{yd}}$;

- at the moment of destruction the plates are separated by hinges of plasticity on separate absolutely rigid disks;

- the breaks location and the number of armatures are defined with minimum area of armature necessary for the plate reinforcement.

a)
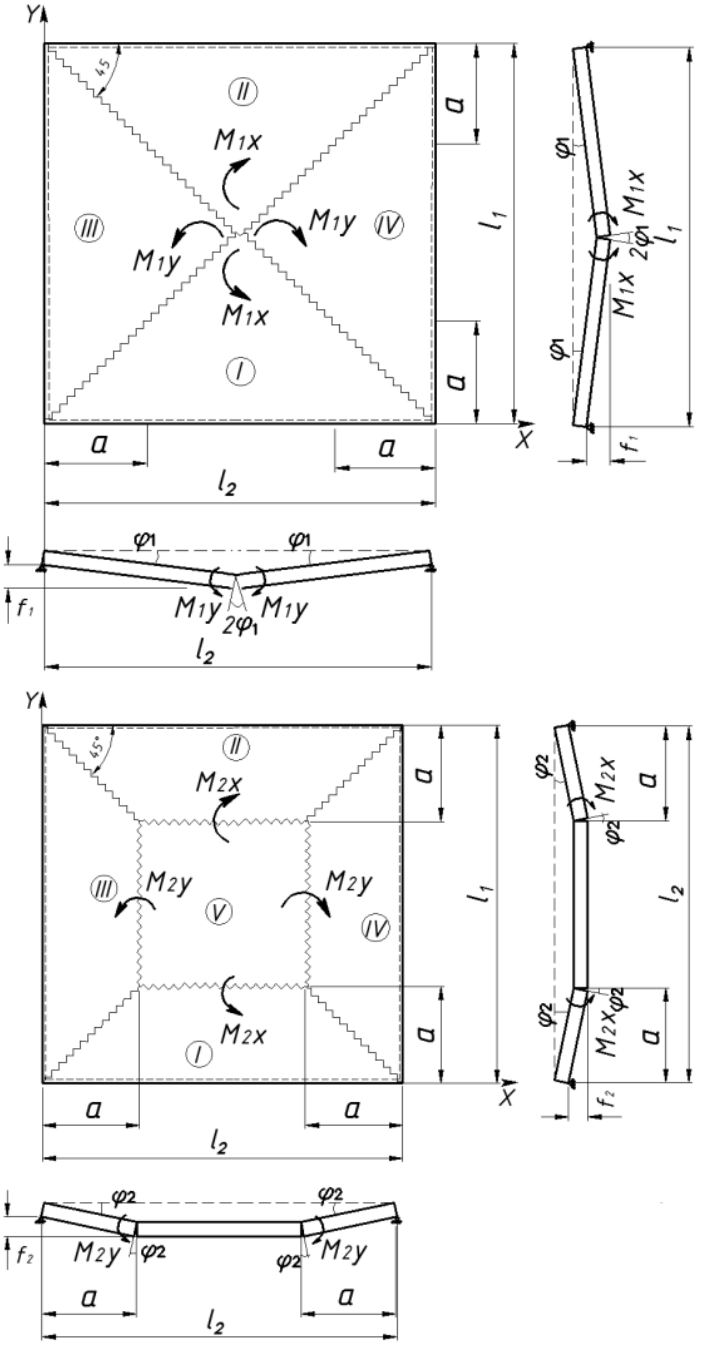

b)

Fig. 3: Kinematic scheme of the plate destruction: a) for the first case of destruction; b) for the second case of destruction.

In accordance with the assumed preconditions for the middle plate, on which only continuous uniformly distributed load with intensi- ty $q$ operates, the equation of virtual works (1) in the first case of destruction (Fig. 3, a) will look like this:

$q V=2\left(M_{1 X}+M_{1 Y}\right) \varphi_{1}$,

where $V$ - the volume of the figure formed by plate discs with their virtual turn around the linear plastic hinges (Fig. 3, a);

$M_{1 X}, M_{1 Y}$ the sum of the projections of limiting bending moments in the linear plastic hinges (Fig. 3) in the planes of the axes $\mathrm{Y}$ and $\mathrm{X}$ respectively.

Let's consider the effect of bending moments in the plate for the first case of the formation of plastic hinges (Fig. 3, a).

In the plate in its limiting state the limiting evenly distributed moments $m_{i}$ and $\bar{m}_{i}$ are acting (Fig. 4), which represent the sum of projections of moments $m_{x}$ and $m_{y}$ on the normal to the linear plastic hinges (Fig. 3, a). The value of moments $m_{x}$ and $m_{y}$ per unit of length can be calculated according to the following expressions:

$\left.\begin{array}{l}m_{x}=\frac{A_{s y} f_{y d} z_{s y}}{S_{x}} \\ m_{y}=\frac{A_{s x} f_{y d} z_{s x}}{S_{y}}\end{array}\right\}$,

where $A_{s x}, A_{s y}$ - the area of one reinforcing rod located along the axes $X$ or $Y$ respectively;

$z_{s x}, z_{s y}$ - the corresponding values of the distance between the internal pair of forces for moments $m_{x}$ and $m_{y}$;

$S_{x}, S_{y}$ - the steps of bars in reinforcing grids along the axes $X$ or $Y$ respectively.

For disk $I$ in figure 3,a according to the scheme on figure 4 the values of the limiting bending moments are determined by dependencies:

$$
\left.\begin{array}{c}
m_{I}=m_{x} \cos \alpha+m_{y} \sin \alpha \\
\bar{m}_{I}=m_{x} \cos \alpha+m_{y} \sin \alpha \\
m_{I a}=k_{m}\left(m_{x} \cos \alpha+m_{y} \sin \alpha\right) \\
\bar{m}_{I a}=k_{m}\left(m_{x} \cos \alpha+m_{y} \sin \alpha\right)
\end{array}\right\},
$$

where $k_{m}$ - the coefficient of reinforcing rods area reduction in the areas where part of the armature is ragged.

If in the section where the reinforcing rods break up, $50 \%$ of their total area remains, then $k_{m}=0,5$.

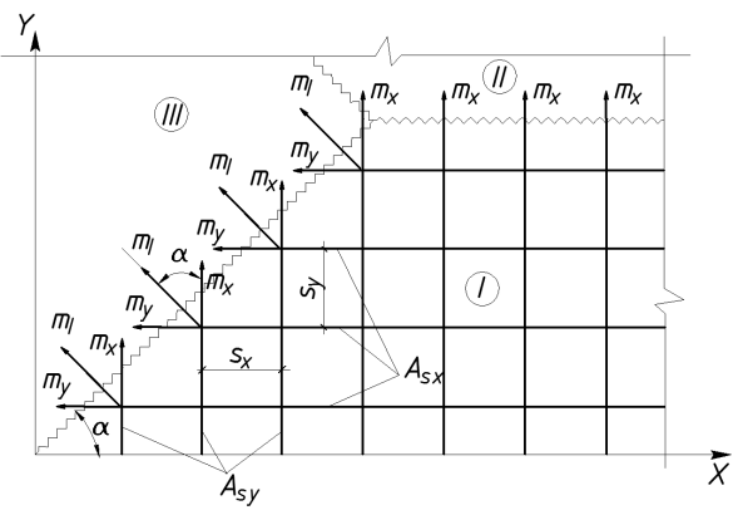

Fig. 4: For determination the limiting bending moments $m_{i}$ and $\bar{m}_{i}$ in plastic linear hinges (for discs I, II and III ). 
Similarly the sum of projections of the limiting bending moments for the discs $I I, I I I$ and $I V$ is determined [12].

Limiting bending moments acting in plastic linear hinges in the presence of breakages or bends of reinforcing rods according to the scheme in Figure 3, a for discs $I$ and $I I$ are determined by the dependence:

$$
M_{1 X}=m_{x}\left(l_{2}-2 a\right)+2 m_{x} k_{m} a=m_{x}\left(l_{2}-2 a\left(1-k_{m}\right)\right)
$$

For discs $I I I$ and $I V$ the value of limiting bending moments is determined by the dependence:

$M_{1 Y}=m_{y}\left(l_{1}-2 a\right)+2 m_{y} k_{m} a=m_{y}\left(l_{1}-2 a\left(1-k_{m}\right)\right)$

For further calculations the following assumptions can be taken:

$$
\left.\begin{array}{l}
n=l_{2} / l_{1}=1 \\
l_{2}=l_{1} \cdot n=l_{1} \\
f_{1}=0,5 l_{1} \varphi_{1}
\end{array}\right\}
$$

Taking into account the accepted assumptions and the scheme of limiting bending moments distribution (Fig. 5), the equation of virtual works (2) will look like this:

$\frac{q l_{1}^{3}(3 n-1)}{6}=2 m_{x}\left(2 a\left(k_{m}-1\right)+l_{1}\right)+2 m_{y}\left(2 a\left(k_{m}-1\right)+l_{1}\right)$

From equation (8) the limiting load on the plate is:

$$
q=\frac{12\left(m_{x}\left(2 a\left(k_{m}-1\right)+l_{1}\right)+m_{y}\left(2 a\left(k_{m}-1\right)+l_{1}\right)\right)}{l_{1}^{3}}
$$

For the second scheme of the plate destruction (Fig. 3,b), when the plastic hinges are formed in the places of armature breakage, the values of the limiting bending moments acting in plastic hinges are determined by the dependencies:

$$
\left.\begin{array}{l}
M_{2 X}=m_{x} k_{m} l_{2} \\
M_{2 Y}=m_{y} k_{m} l_{1}
\end{array}\right\} .
$$

Taking into account accepted simplifications (4) and the scheme of limiting bending moments distribution (Fig. 3,a and 3,b), the equation of virtual work for this case will look like this:

$$
q\left(\frac{4}{3} a^{3}-2 a^{2} l_{1}+a \cdot l_{1}^{2}\right)=2 m_{x} k_{m} l_{2}+2 m_{y} k_{m} l_{1}
$$

The limiting load on the plate:

$$
q=\frac{6 l_{1} k_{m}\left(m_{x} n+m_{y}\right)}{4 a^{3}-3 a^{2} l_{1}(1+n)+3 a \cdot l_{1}^{2} \cdot n}
$$

If to equate the expression (9) to the expression (12) and to perform the appropriate transformation at $a=k_{l} \cdot l_{1}$ and $m_{y}=m_{x} k_{n}$, then we will obtain the equation relatively to $k_{l}=a / l_{1}$ :

$$
4\left(4 k_{l}^{3}-6 k_{l}^{2}+3 k_{l}\right)\left(4 k_{l}\left(k_{m}-1\right)+1+k_{n}\right)-2 k_{m}\left(1+k_{n}\right)=0
$$

The equation (13) is solved relatively to $k_{l}$ at a given value $k_{m}$. In real conditions when $50 \%$ of the armature rods will be torn $k_{m}=0,5$.

For plates between columns, in accordance with Fig. 2, the following prerequisites are adopted as for middle plates. Kinematic schemes for two cases of destruction are shown in Fig. 5.

For the case when the plate is destroyed by the first scheme (Fig. 5, a), the equation of virtual works (1) will look like this:

$$
\frac{q l_{1} l_{2} f_{1}}{2}+\frac{q^{r} l_{2} f_{1}}{3}=2 M, \varphi
$$

The limiting bending moment, which can perceive the plastic hinge, is determined by the dependence:

$$
M_{1}=m_{y} l_{1}
$$

a)
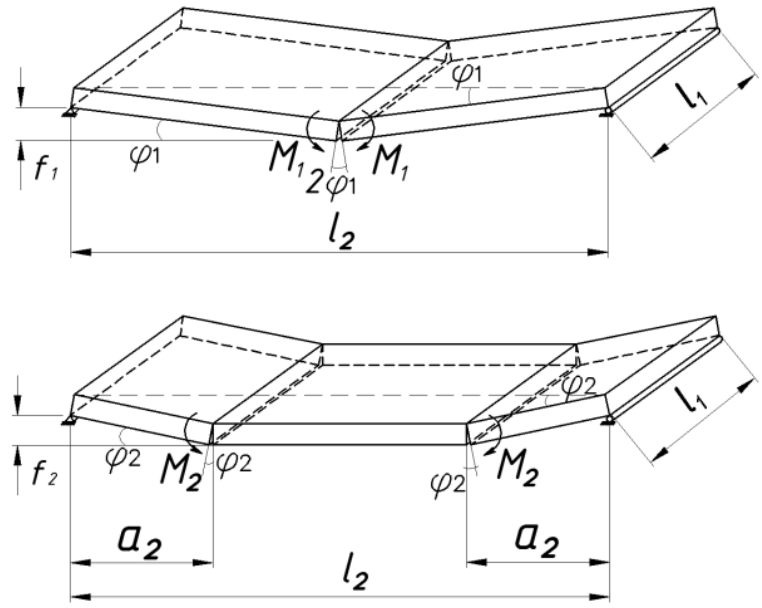

Fig. 5: The schemes of the linear plastic hinges formation in the plate between columns: a) for the first case of destruction; b) for the second case of destruction.

If to take into account the fact that the plate between the columns has a square shape $\left(l_{1}=l_{2}\right)$, displacement in the middle of the plate $f_{1}=0,5 l_{2} \varphi_{1}$ at $\varphi_{1} \approx \operatorname{tg} \varphi_{1}$, and the load from the middle plate $q^{T}=0,5 q l_{1}$, the equation of virtual works (4) will look like this:

$$
\frac{q l_{1}^{3}}{4}+\frac{q l_{1}^{3}}{6}=2 m_{y} l_{1}
$$

The boundary load on the plate between the columns will be equal to:

$$
q=\frac{24 m_{y}}{5 l_{1}^{2}}
$$

For a case in which plastic hinges are formed in the places of the armature breakage (Fig. 5, b), the limiting bending moment, which can be perceived by plastic hinges, is:

$M_{2}=m_{y} k_{m} l_{1}$

where $k_{m}=M_{2} / M_{1}$. 
The equation of virtual work for this case will look like this:

$$
q\left(l_{1}^{2} a_{2}-l_{1} a_{2}^{2}\right) \varphi_{2}+q \frac{3 l_{1}^{2} a_{2}-4 a_{2}^{3}}{6} \varphi_{2}=2 m_{y} k_{m} l_{1} \varphi_{2}
$$

The bearing capacity of the plate will be determined by dependence:

$$
q=\frac{12 m_{y} k_{m} l_{1}}{a_{2}\left(9 l_{1}^{2}-6 l_{1} a_{2}-4 a_{2}^{2}\right)}
$$

If to equate the expression (17) to the expression (20) and to perform the appropriate transformation at $k_{l}=a_{2} / l_{1}$, then we will obtain the equation relatively to $k_{l}$ :

$$
-8 l^{3} k_{l}^{3}-12 l^{3} k_{l}+18 l^{3} k_{l}-5 l_{l}^{3} k_{m}=0
$$

The numerical solution of this equation at $k_{m}=0,5$ gives the result $k_{l}=0,157$.

The area of the working armature in the plate is determined by the formula:

$$
A_{s x}=\frac{5 q l_{1}^{2} S_{y}}{24 f_{y d} Z_{s x}}
$$

For plates above columns the kinematic schemes for two cases of destruction are shown in Fig. 6.

a)
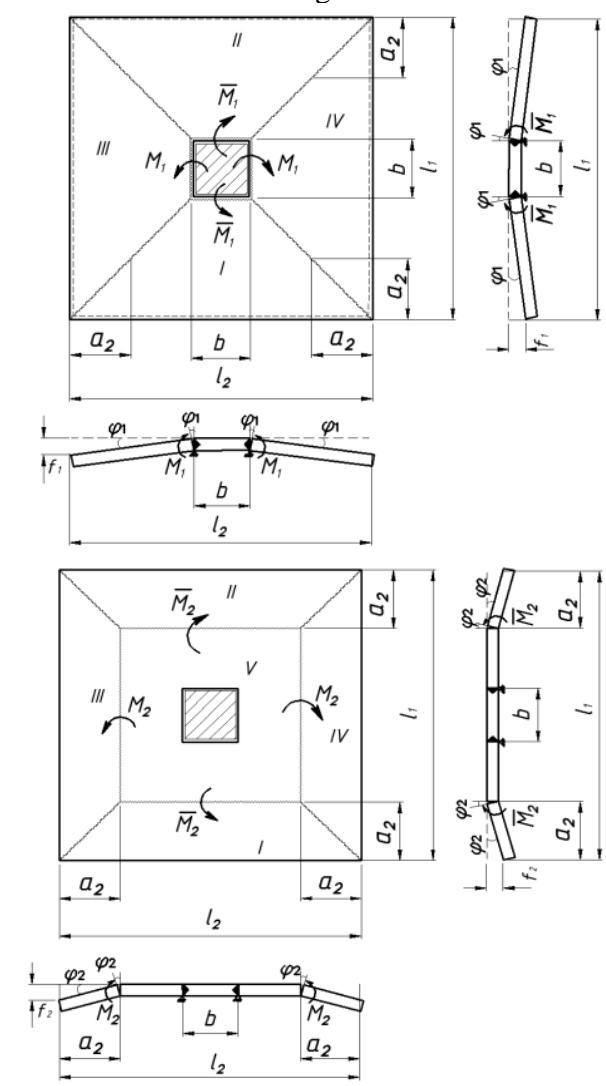

Fig. 6: The formation of linear plastic hinges in the plate above the column: a) for the first kinematic scheme; b) for the second kinematic scheme.
For the first case of destruction in accordance with the kinematic scheme in Figure 6a, the equation of virtual works (1) will look like this:

$$
q V_{1}+q^{\Pi} l_{1} f_{1}=2\left(M_{1}+\overline{M_{1}}\right) \varphi_{1}
$$

where $V_{1}$ - the volume of the figure which is formed as a result of the discs rotation around the axes that pass on the edges of the plate hole (Fig. 6a):

$V_{1}=l_{1} l_{2} f_{1}-\frac{f_{1}}{3}\left(l_{1} l_{2}+\sqrt{l_{1} l_{2}} \cdot b+b^{2}\right)$

$M_{1}, \bar{M}_{1}-$ the sums of limiting bending moments projections in linear plastic hinges.

Whereas the plate over the column has a square shape $\left(l_{1}=l_{2}\right)$, the displacement in the middle of the plate $f_{2}=a \varphi_{2}$ at $\varphi_{2} \approx \operatorname{tg} \varphi_{2}$, and the load $q^{\Pi}=0,75 q l_{1}$, the equation of virtual work for the second case of destruction:

$q V_{2}+0,75 q l_{1}^{2} f_{2}=2\left(M_{2}+\bar{M}_{2}\right) \varphi_{2}$

where $V_{2}$ - the volume of the figure which is formed as a result of the discs rotation around the axes that pass through the lines of the armature breakage (Fig. 6, b).

$V_{2}=l_{1} l_{2} f_{2}-\frac{f_{2}}{3}\left(l_{1} l_{2}+\sqrt{l_{1} l_{2}\left(l_{1}-2 a\right)\left(l_{2}-2 a\right)}+\right.$

$\left.+\left(l_{1}-2 a\right)\left(l_{2}-2 a\right)\right)$

Considering the expressions (23) and (25) as a system of two equations, taking into account the dependences (4), (24) and (26), the bearing capacity of the plate over the column is determined by the dependence

$q=\frac{12 m_{x} k_{m} l_{1}}{\left.a^{2}\left(6 l_{1}-4 a\right)+9 l_{1}^{2}\right)}$

At a given value $k_{m}=0,5$ optimal value $a=l_{1} \cdot k_{l}$ will be at $k_{l}=0,312$.

If to analyze the scheme of columns' loading with constant and temporary loads within the same floor (Fig. 7), two cases of column loading can be distinguished [13]:

- first one - the central compression;

- second one - the noncentral (oblique) compression. 


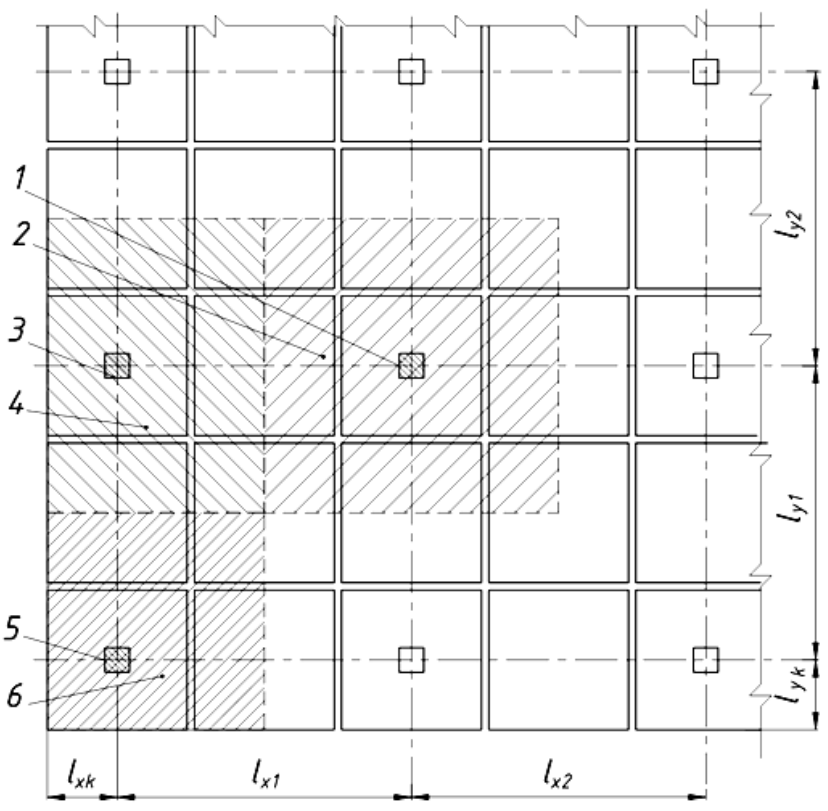

Fig. 7: The fragment of the overlap construction: 1 - centrally-compressed column; 2 - loading area for the central compressed column; 3 - noncentrally compressed column; 4 - loading area for noncentrally compressed column; 5 - oblique pressed column; 6 - the loading area for the obliquely compressed column.

For calculating the bearing capacity of columns in first and second cases the estimated values are: constant $\mathrm{g}\left(\mathrm{kN} / \mathrm{m}^{2}\right)$ and temporary $\mathrm{v}\left(\mathrm{kN} / \mathrm{m}^{2}\right)$ loads from the overlapping over the column; full $N(\mathrm{kN})$ and temporary $\mathrm{Nl}(\mathrm{kN})$ load on the column from all above-ground floors. Also are required: the height of the floor $H_{f}(\mathrm{~m})$; the estimated length of the column $l_{O}=H_{\Pi}$; the cross-sectional dimensions of the column $\mathrm{b} \times \mathrm{h}(\mathrm{mm})$; the calculating characteristics of concrete $f_{c d}, E_{c}, \varepsilon_{c d}, \varepsilon_{c u l}$; the calculating characteristics of the armature $f_{y d}, E_{S}, \varepsilon_{c 1}, \varepsilon_{u d}$.

For calculating the columns in the second case of loading, the bending moment in the plane of height $h$ from the action of the total external load $(g+v)$ on the area of overlap $A$ above the column will be determined by the formula:

$M=0,5 \cdot(g+v) \cdot A \cdot h$

where $h$ - the transverse dimension of the column in the plane of bending moment action.

The moment from permanent and long-term external load action on the overlap above the column

$M l=0,5 \cdot\left(g+v_{l}\right) \cdot A \cdot h$

The estimated eccentricity in this plane for noncentrally compressed columns:

$$
e_{0}=M / N
$$

For the case of a column oblique compression at $l_{y k}+l_{y 1} \leq l_{x k}+l_{x 1}$ (Fig. 7) the eccentricities of the longitudinal force application for mutually perpendicular planes [14]:

$e_{0 x}=M / N, \quad e_{o y}=e_{O x} \cdot \frac{l_{y 1}-2 \cdot l_{y k}}{l_{x 1}-2 \cdot l_{x k}}$

The formulas obtained from the analysis of the columns loading scheme will allow to implement the static calculation of the constructive system without using beams and capitals.
In general, it is recommended to calculate the strength of the oblique noncentrally compression from the equilibrium condition of the noncentrally compressed element according to the calculating scheme presented in Fig. 8. According to this scheme:

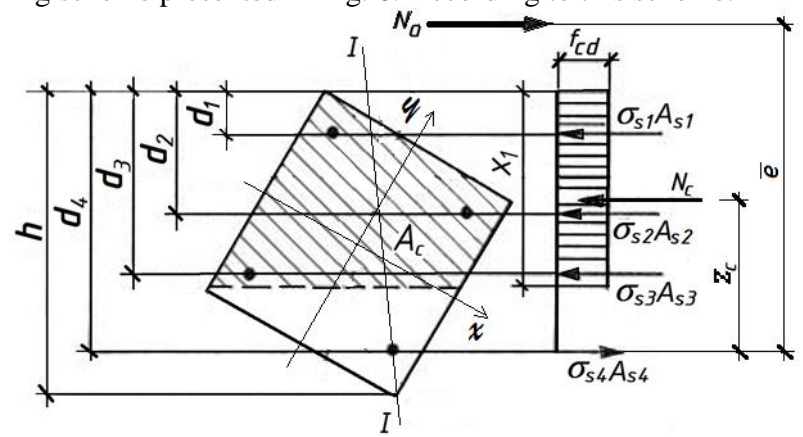

Fig. 8: The scheme of reinforced concrete element stress-deformed state at oblique compression

$N_{0} \cdot \bar{e}=f_{c d} S_{c}-\Sigma \sigma_{s i} S_{s i}$

where $\bar{e}-$ the distance from the line of the applied longitudinal force $N_{O}$ action to the axis passing through the center of gravity of the most distant stretched rod section;

$S_{c}$ - the static moment of the area of concrete compressed zone relatively to the same rod,

$S_{c}=A_{c} z_{c}$

$\sigma_{s i}$ - the tension in the $i-$ th rod of longitudinal reinforcement; $S_{S i}$ - the static moment of the $i-$ th rod of longitudinal reinforcement relatively to the most distant stretched rod; $z_{c}$ - the distance from the point of resultant stresses in the concrete compressed zone $N_{c}$ application to the most distant stretched rod.

$f_{c d} A_{c}-\Sigma \sigma_{s i} A_{s i}-N_{0}=0$

The sign of tension $\sigma_{s i}$ in rods is determined by the coefficient $k_{i}=\left(x_{1}-d_{i}\right) /\left|x_{1}-d_{i}\right|$ and is entered with the corresponding signs: plus means stretching, and minus - compression.

The height of the compressed zone $X_{1}$ and tension are determined from the joint solution of equations (32) and (34).

The solving of equations (32) and (34) as a system is a complicated task, especially when in the scheme on fig. 8 the deformation model is used. The determination of the neutral line position is performed by the method of successive approximations. To determine the position of the neutral line must be observed additional conditions: the point of external force $N_{O}$ application, the resultant compression efforts in concrete $N_{C}$, in compressed armature $N_{S}^{/}$and in stretched armature $N_{S}$ must lie on one line I - I (Fig. 8). In order to simplify calculations in practical tasks of determining the bearing capacity is proposed to implement simplified formulas. Their essence is in following. The bearing capacity of an element with oblique noncentral compression can be described by some surface (Fig. 9). Each point on this surface is characterized by four variable parameters $N, M_{x}, M_{y}$ and the angle of the power plane $\beta$. If the point with the parameters $N_{i}$, $M_{x i}, M_{y i}$ and $\beta_{i}$ gets inside the volume which bounded by the surface of the bearing capacity, the bearing capacity of the element is ensured. 


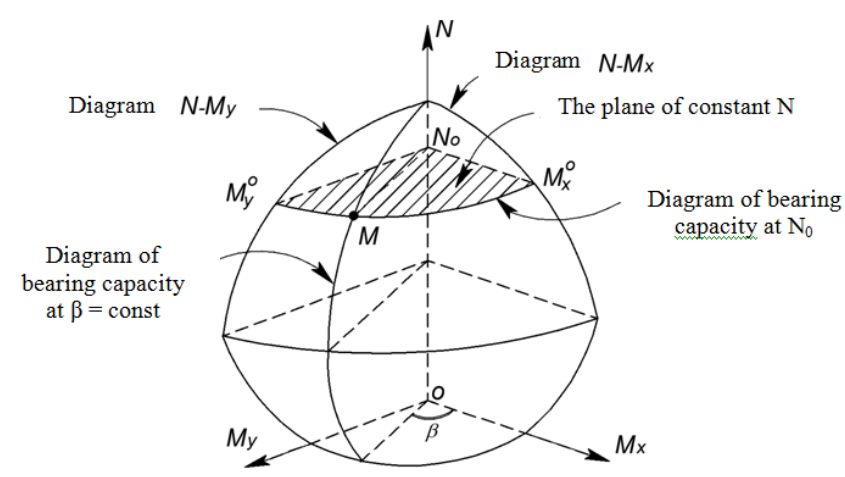

Fig. 9: The surface of the bearing capacity of the element with oblique compression

Practical methods of calculation at oblique compression of columns in constructive system without using beams and capitals lies in the calculation of their bearing capacity for a given geometrical dimensions $h, b, a_{S}, a_{S}^{\prime}$, reinforcement area $A_{S i}$ and strength characteristics of concrete $f_{c d}$ and armature $f_{y d}$.

Using the accepted model, the checking of bearing capacity the columns with rectangular section and symmetrically located armature in the form of 4 rods at the corners of the section (Figure 8) can be performed on the condition:

$$
\left(\frac{M_{x}}{M_{x}^{o}}\right)^{k}+\left(\frac{M_{y}}{M_{y}^{o}}\right)^{k} \leq 1
$$

where $M_{x}$ and $M_{y}$ - the moments from the external load relatively to the center of gravity of the section in symmetry planes $x$ and $y$;

$M_{x}^{o}$ and $M_{y}^{o}$ - the internal limiting moments relatively to the center of gravity of the section in symmetry planes $x$ and $y$. According to the scheme on fig. 8 :

$$
M_{x}^{o}\left(M_{y}^{o}\right)=f_{c d} \cdot b \cdot x(d-0,5 x)+\left(f_{y d} A_{s}^{\prime}-N / 2\right)\left(d-a_{s}^{\prime}\right)
$$

where $A_{S}^{\prime}$ - the area of reinforcement in the compressed zone of concrete relatively to $x$ or $y$,

at $\alpha_{n}=\frac{N}{f_{c d} \cdot b \cdot d} \leq \xi_{R} \rightarrow x=\alpha_{n} \cdot d$

and at $\alpha_{n}>\xi_{R} \rightarrow x=\frac{\alpha_{n} \cdot\left(1-\xi_{R}\right)+2 \cdot \alpha_{s} \cdot \xi_{R}}{1-\xi_{R}+2 \cdot \alpha_{S}} \cdot d$

where $a_{s}=\frac{f_{c d \cdot A_{s}}}{f_{c d} \cdot b \cdot d}$

$A_{S}$ - the area of reinforcement in the stretched concrete zone relatively to $x$ or $y$.

The exponent $k$ is recommended to determine the following formulas: if $\alpha_{n} \leq 0,4$, then

$$
k=\frac{3,44-0,023 a_{s}}{0,254+a_{s}} \cdot\left(0,4-a_{n}\right)^{2}+\frac{0,275+a_{s}}{0,16+a_{s}}
$$

if $\alpha_{n}>0,4$, then

$$
\begin{aligned}
k & =\left[\frac{\left(1,7-a_{s}\right)^{2}}{4}+0,1775\right]\left(a_{n}^{2}-0,16\right)+\frac{0,275+a_{s}}{0,16+a_{s}} \leq 1,6 \\
\alpha_{s} & =\frac{f_{y d} \cdot A_{s, t o t}}{f_{c d} \cdot b \cdot d}
\end{aligned}
$$

where $A_{s, t o t}$ - the total area of reinforcement in the column section.

\section{Conclusion}

1. The constructive system without using beams and capitals is promising for the construction of residential and public buildings. 2 . The application of the kinematic method of the limiting equilibrium theory gives an opportunity to calculate the optimal reinforcement and to take into account the plate support scheme and the nature of applying the load to them.

3. Plates with breaks of longitudinal reinforcement are better satisfying the conditions of internal forces distribution, which allows reducing the cost of reinforcing steel by $15 \%$.

4. To calculate the bearing capacity of the columns in the frame without using beams and capitals it is possible to use the simplified engineering technique represented by the formulas (35) - (42) The advantage of the proposed method is the ability to control the strength of the columns in each plane of the sections, which allows them to perform their optimization design taking into account the complex longitudinal deformation.

\section{References}

[1] Pavlikov, A. M. Bezkapitelno-bezbalkova karkasno-konstruktyvna systema budivli: osoblyvosti ta dosvid vykorystannya pid dostupne zhytlo / A.M. Pavlikov, YE.M. Babych, B.M. Petter // Budivelni konstruktsiyi: mizhvidomchyy naukovo-tekhnichnyy zbirnyk naukovykh prats' (budivnytstvo) / DP DND IBK. - Issue 78: in 2 books. Book 1. - Kyiv: DP NDIBK, 2013. - pp. 28 - 46.

[2] What is "KUB-2.5", available online: http://zavod-zhhi.com.ua.

[3] Description of the system according to the information of the NGO "KUB", available online: http://kub-invest.ru/sist.html.

[4] Description of the system "KUB-2,5", available online: http://www.pi2.ru.

[5] Unifitsirovannaya sistema sborno-monolitnogo bezrigel'nogo karkasa. Osnovnyye polozheniya po raschetu, montazhu i komponovke zdaniy: a working project in 9 editions. The series "KUB-2,5". Issue 1-1. / Firm "KUB" JV "IN-EX", Scientific-design and construction association of monolithic housing construction (NSPO "MONOLIT"). - Moscow: 1990. - 49 p.

[6] Dorfman, A.E. Proyektirovaniye bezbalochnykh beskapitel'nykh perekrytiy / A.E. Dorfman, L.N. Levontin. - Moscow: Stroiizdat, 1975. $-124 \mathrm{p}$.

[7] Shuenn-Yih Chang, Experimental Studies of Reinforced Concrete Bridge Columns under Axial Load Plus Biaxial Bending, Journal of Structural Engineering, Vol. 136, No 1(12), (2010), pp. 12-18, https://doi.org/10.1061/(ASCE)0733-9445(2010)136:1(12).

[8] L. Pallarés, J.L. Bonet, P.F. Miguel, M.A. Fernández Prada, Experimental research on high strength concrete slender columns subjected to compression and biaxial bending forces, Engineering Structures, Vol. 30, No 7, (2008), pp. 1879-1894, https://doi.org/10.1016/j.engstruct.2007.12.005.

[9] J.L. Bonet, M.L. Romero, P.F. Miguel, Effective flexural stiffness of slender reinforced concrete columns under axial forces and biaxial bending, Engineering Structures, Vol. 33, No. 3, (2011), pp. 881-893, https://doi.org/10.1016/j.engstruct.2010.12.009.

[10] Piskunov, V.G. Modeling of transverse shears of piecewise homogeneous composite bars using an iterative process with account of tangential loads / V.G. Piskunov, A.V. Goryk, V.N. Cherednikov // Mechanics of Composite Materials. - Volume 36, Issue 4, July 2000, Pages 287-296.

[11] Bishnu P. A new method of applying long-term multiaxial stresses in concrete specimens undergoing ASR, and their triaxial expansions [Text] / P. G. Bishnu, K. P. Daman // Materials and Structures. 
- 2016. - Vol. 49 (9). - pp. 3409-3508. - doi: 10.1617/s11527-0150734-z.

[12] J.L. Bonet, M.H.F.M. Barros, M.L. Romero, Comparative study of analytical and numerical algorithms for designing reinforced concrete sections under biaxial bending, Computers \& Structures, Vol. 84, No. 31-32, (2006), pp. 2184-2193, https://doi.org/10.1016/j.compstruc.2006.08.065.

[13] Hasenko A.V. Causes of the eccentric compression reinforced concrete elements fixed joint stanchion and rafter gable frame of agricultural buildings / A.V. Hasenko, I.A. Yurko, O.G. Fenko, P.A. Yurko // The International Scientific Periodical Journal "Modern Technology and Innovative Technologies". - Germany: Karlsruhe, 2017. - Issue №2, Vol.2. - pp. 126 - 129. - doi: 10.21893/2567-5273.2017-02-02-033.

[14] Jin-Keun Kim, Sang-Soon Lee, The behavior of reinforced concrete columns subjected to axial force and biaxial bending, Engineering Structures, Vol. 22, No. 11, (2000), pp. 1518-1528, https://doi.org/10.1016/S0141-0296(99)00090-5. 